\title{
Pine Needle (Pinus densiflora) Extract-Mediated Synthesis of Silver Nanoparticles and the Preparation of Carrageenan-Based Antimicrobial Packaging Films
}

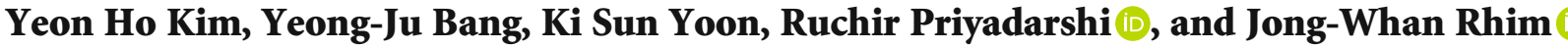 \\ Department of Food and Nutrition, Kyung Hee University, 26 Kyungheedae-ro, Dongdaemun-gu, Seoul 02447, Republic of Korea \\ Correspondence should be addressed to Ruchir Priyadarshi; ruchirpriyadarshi@gmail.com \\ and Jong-Whan Rhim; jwrhim@khu.ac.kr
}

Received 19 November 2021; Revised 9 December 2021; Accepted 10 February 2022; Published 27 February 2022

Academic Editor: David Cornu

Copyright () 2022 Yeon Ho Kim et al. This is an open access article distributed under the Creative Commons Attribution License, which permits unrestricted use, distribution, and reproduction in any medium, provided the original work is properly cited.

\begin{abstract}
Silver nanoparticles (AgNPs) were prepared using a pine needle extract-mediated synthesis method. The X-ray diffraction (XRD) spectrum showed a characteristic peak of silver, indicating that crystalline silver nanoparticles were formed. The synthesized AgNPs were spherical and had a uniform size of $63.9 \pm 2.1 \mathrm{~nm}$ with a narrow size distribution. The AgNPs have been used as functional nanofillers in the manufacture of carrageenan-based functional nanocomposite films. Field emission scanning electron microscopy (FE-SEM) confirmed that AgNPs were uniformly dispersed in the carrageenan polymer matrix. The addition of AgNPs to the Carr film affected the surface color, mechanical, water vapor barrier, and surface wettability properties and significantly improved the UV blocking properties of the nanocomposite films. In addition, the carrageenan/ AgNP composite films showed strong antioxidant activity and potent antibacterial activity against both Gram-positive ( $S$. aureus) and Gram-negative (E. coli O157: H7) bacteria. The carrageenan/AgNP film with UV protection, antioxidant, and antibacterial activity can be used as active food packaging material to extend the shelf life of packaged food.
\end{abstract}

\section{Introduction}

The current food packaging industry makes use of enormous amounts of petroleum-based synthetic plastic materials due to their outstanding properties such as light-weight, mechanical strength, toughness, transparency, and ability to be molded into rigid as well as flexible forms [1]. Although the packaging industry relies heavily on synthetic plastics, we have witnessed the adverse environmental impacts of these nonbiodegradable materials in recent years [2]. Therefore, the current scenario makes the research on biodegradable materials essential. Carrageenan is a renewable polysaccharide obtained from various species of Rhodophyta (marine red algae), which is one of the most popular materials for food packaging application due to its good film-forming property, eco-friendliness, biocompatibility, and renewability $[3,4]$. Carrageenan is a water-soluble sulfated polysaccharide and consists of long linear chains of D-galactose and D-anhydrogalatose [4]. Depending on the number and allocation of sulfated ester pattern on 3,6anhydro-D (or L)-galactose residues, carrageenan can be classified into kappa, iota, and lambda forms [5]. Kappa carrageenan exhibits the best film formation and an excellent moisture barrier and mechanical properties [6]. Carrageenan is a suitable candidate for active packaging applications due to its ability to carry and appropriately release functional components such as nanoparticles [3, 7].

With the advent of nanotechnology, the past couple of decades has witnessed the synthesis and utilization of various metal nanoparticles for numerous applications. The properties of nanoparticles could be influenced by various conditions such as size, surface condition, and capping agents. Shankar and Rhim reported that five different sizes of $\mathrm{ZnO}$ nanoparticles displayed different trends in the antimicrobial activity against $E$. coli and $S$. epidermis, showing the strongest antimicrobial activity with the smallest sized particles [8]. The shape of nanoparticles was technologically important and related to optical, electrical, and catalytic 
properties [9]. The antimicrobial activity of sulfur nanoparticles was governed by capping agents, where chitosancapped sulfur nanoparticles had a stronger antimicrobial activity than the uncapped ones [10]. Therefore, to engineer the properties of the nanoparticles, size, shape, and capping agent are paramount factors.

Silver nanoparticles (AgNP) have long been used as antimicrobial agents against various pathogenic microorganisms, particularly food-borne bacterial strains $[11,12]$. Therefore, AgNPs have also been widely used as fillers for antibacterial food packaging nanocomposite films [13, 14]. AgNPs were synthesized by various methods [11, 12]. Chemical synthesis is considered the most efficient synthesis method for metallic nanoparticles. Despite the strength of these chemical methods, such as low cost for high yield, these lead to residual toxic solvents and hazardous byproducts [15]. Hence, to solve these problems, the development of high-yield, nontoxic, low-cost, and environmentally friendly routes for the synthesis of nanoparticles is in demand [16]. To this end, in a recent report, Ismail et al. synthesized silver iodide nanoparticles using a simple laser ablation technique without chemical reducing agents [17]. The particles showed excellent antimicrobial activity against a wide range of microorganisms, especially against Gramnegative bacterial strains. Besides, various studies on the green synthesis of AgNPs have been published [5, 11, 16, $18,19]$. For example, Jabir et al. performed the green synthesis of AgNPs using Eriobotrya japonica extract, which has been successfully used in anticancer therapy [20]. However, continuous research is being carried out to make the process increasingly sustainable.

Pinus densiflora, popularly known as the Korean or Japanese red pine, is classified as a member of the family Pinaceae. Despite its origins from the East-Asian countries, it has been widely distributed around the world. Since ancient times, it has been used as food or dietary supplements to promote health [21]. The leaves of $P$. densiflora have a needle-like appearance and hence are commonly referred to as pine needles. Since $P$. densiflora does not follow the seasonal leaf abscission and remains green in all seasons, pine needles have the advantage of being a continuously renewable natural resource. The essential oil extracted from $P$. densiflora pine needles contains components such as flavonoids, chlorophyll, pinitol, $\alpha$-pinene, $\beta$-pinene, camphene, vitamin A, and vitamin C [22]. Due to the presence of these components, the pine needle extract displays various functional properties. Venkatesan et al. reported that the pine needle extracts prepared using $40 \%$ ethanol exhibited the highest antioxidant effect among those prepared using $0,20,40,60,80$, and $100 \%$ ethanol [23]. Also, pine needle extracts from $70 \%$ ethanol had antimicrobial activity against skin pathogens such as $S$. aureus, $S$. epidermidis, $P$. acnes, $C$. albicans, and C. tropicalis [24]. Despite these medicinal and functional properties of $P$. densiflora, it could not attract the attention of researchers, and the studies involving this species have been limited.

For the first time, this study explores a green method for synthesizing AgNPs using Pinus densiflora needle extract as a reducing agent and stabilizer. The AgNPs prepared in this way are expected to have various functions such as antibacterial and antioxidant activity by the polyphenol compound of pine needles in addition to the intrinsic properties of silver nanoparticles. The carrageenan-based films incorporated with AgNP were fabricated, and their structural and physicochemical properties were assessed. Also, the functional properties such as the antimicrobial and antioxidant activity of the films were studied to ascertain the potential in active food packaging applications.

\section{Materials and Methods}

2.1. Materials. Pine needles were collected from the Gowhang-mountain (Seoul, Korea). Silver nitrate was purchased from Duksan Pure Chemicals Co., Ltd. (Gyeonggido, Korea). $\kappa$-carrageenan was purchased from Hankook Carrageenan (Jeonnam, Korea). Glycerol was obtained from Daejung Chemicals \& Metals Co., Ltd. (Siheung, Gyeonggido, Korea). Tryptic soy broth (TSB) and tryptic soy agar (TSA) were obtained from KisanBio (Seoul, Korea). Staphylococcus aureus (ATCC 13565) and E. coli O157: H7 (KCCM 11235) were obtained from Koran Culture Center of Microorganisms (KCCM, Seoul, Korea).

2.2. Pine Needle Extract. Pine needle leaves were washed with water and dried in a hot air oven at $50^{\circ} \mathrm{C}$ for 4 days. $100 \mathrm{~g}$ of the dried samples were blended with $1 \mathrm{~L}$ of distilled water for $2 \mathrm{~min}$. The mixture was heated at $80^{\circ} \mathrm{C}$ for 3 days while stirring using a magnetic bar before filtration using Whatman no. 1 (Whatman, Inc., Maidstone, UK) filter paper. The filtered extract was concentrated using a rotary evaporator (N-1200A, Eyela, Shanghai, China) at $70^{\circ} \mathrm{C}$ temperature and 100 Torr pressure. The concentrated extract was reconstituted in $100 \mathrm{~mL}$ distilled water and dried using a freeze dryer (FD8508, Ilshin BioBase, Seoul, Korea).

2.3. Synthesis of AgNP. Silver nanoparticles were synthesized by reducing silver nitrate using pine needle extract. $1 \mathrm{~g}$ of the pine needle extract powder was mixed in $100 \mathrm{~mL}$ of distilled water. The mixture was heated at $100^{\circ} \mathrm{C}$ while stirring using a magnetic bar. After that, $0.17 \mathrm{~g}$ of silver nitrate was added to the solution and stirred for $1 \mathrm{~h}$. Following this, the reaction mixture was centrifuged at $10,000 \mathrm{rpm}$ for $20 \mathrm{~min}$ to collect the sediment and washed at least three times with distilled water. The washed residue was dried in a hot-air oven at $80^{\circ} \mathrm{C}$ for $48 \mathrm{~h}$ to obtain AgNP.

2.4. Characterizations of AgNP. The formation of AgNP in solution was confirmed using a UV-vis spectrophotometer (Mecasys Optizen POP Series UV/Vis, Seoul, Korea) by obtaining an absorption spectrum in the range of 200$700 \mathrm{~nm}$. Particle size of AgNP was analyzed using ImageJ software (ImageJ 1.46r, National Institute of Health, USA). Morphology of the synthesized nanoparticles was observed using a field emission scanning electron microscope (FESEM, S-4800, Hitachi Co., Ltd, Matsuda, Japan). To confirm the capping of silver nanoparticles by pine needle extract, FT-IR spectra of pine needle extract and AgNP were obtained using Fourier transform infrared spectrophotometer (TENSOR 37 Spectrophotometer, Billerica, MA, USA) 
for analysis and comparison. For this, $\mathrm{KBr}$ pellets of pine needle extract and AgNP $(1: 100 w / w)$ were prepared, and the spectra were recorded in the range $4000-400 \mathrm{~cm}^{-1}$.

2.5. Fabrication of Carr/AgNP Nanocomposite Films. The carrageenan films incorporated with AgNP were prepared using a solution casting method [5]. Briefly, $1.2 \mathrm{~g}$ glycerol was added to $120 \mathrm{~mL}$ distilled water and mixed while stirring. Following this, the temperature was raised to $80^{\circ} \mathrm{C}$, and carrageenan powder $(4 \mathrm{~g})$ was added while stirring continuously. The biopolymer was allowed to dissolve completely, and AgNP was added in varying concentrations $(1,2$, and $3 \mathrm{wt} \%$ of carrageenan). Then, the film-forming solutions were cast on Teflon film (Cole-Parmer Instrument Co., Chicago, IL, USA)-coated glass plate $(24 \mathrm{~cm} \times 30 \mathrm{~cm})$ and dried at room temperature $\left(25 \pm 2^{\circ} \mathrm{C}\right)$ for three days. The dried films were peeled off the glass plates and preconditioned in a humidity chamber at $25^{\circ} \mathrm{C}$ and $50 \% \mathrm{RH}$ for at least $48 \mathrm{~h}$ before testing. Each film was prepared in triplicates, and the samples were denoted as Carr, Carr/AgNP ${ }^{1 \%}$, Carr $/ \mathrm{AgNP}^{2 \%}$, and Carr $/ \mathrm{AgNP}^{3 \%}$ according to the content of AgNP.

2.6. Characterization of Carr/AgNP Nanocomposite Films. The microstructure of the films was observed using a field emission scanning electron microscope (S-4800, Hitachi Co., Ltd., Matsuda, Japan). For this, a small section of each composite film was mounted on carbon tape and analyzed using an acceleration voltage of $2 \mathrm{kV}$.

The films' X-ray diffraction (XRD) pattern was acquired using an X-ray diffractometer (PANalytical X'pert pro MRD diffractometer, Amsterdam, Netherlands). Each film sample was cut into a rectangular shape $(2.5 \times 2.5 \mathrm{~cm})$ and placed on a glass sample holder for testing. The spectra were analyzed using a $\mathrm{Cu}-\mathrm{K} \alpha$ radiation source and a nickel monochromator filter at $40 \mathrm{kV}$ and $30 \mathrm{~mA}$ with a scan rate of $4^{\circ} /$ min within the range $2 \theta=30-80^{\circ}$.

Fourier transform infrared (FT-IR) spectra of the films were obtained using a TENSOR37 FT-IR spectrophotometer with OPUS 6.0 software (Billerica, MA, USA) operated at a resolution of $4 \mathrm{~cm}^{-1}$ within the range $4000-500 \mathrm{~cm}^{-1}$.

\subsection{Physicochemical Properties of Carr/AgNP Nanocomposite Films}

2.7.1. Surface Color and Optical Properties. The surface color of the nanocomposite films was measured using a chroma meter (Minolta, CR-200, Tokyo, Japan) with a white color plate as a standard background $(L *=97.75, a *=-0.49$, and $b *=1.96)$. The CIE color values $(L * a *$, and $b *)$ were determined by measuring a mean of the values obtained at five different positions on each film sample. Total color difference $(\Delta E)$ was calculated as follows:

$$
\Delta E=\sqrt{\left[(\Delta L *)^{2}+(\Delta a *)^{2}+(\Delta b *)^{2}\right]},
$$

where $L * a *$, and $b *$ are the difference between color values of the standard white plate and film specimen, respectively.
To measure the film samples' optical properties, UVvisible spectra of nanocomposite films were analyzed using a UV-vis spectrophotometer (Model 8451A, HewlettPackard Co., Santa Alara, CA USA) in the wavelength range 200-700 $\mathrm{nm}$. The UV-blocking property and transparency of the composite films were estimated by measuring the transmittance values at $280 \mathrm{~nm}\left(T_{280 \mathrm{~nm}}\right)$ and $660 \mathrm{~nm}\left(T_{660 \mathrm{~nm}}\right)$ wavelengths, respectively.

\subsubsection{Water Vapor Permeability (WVP) and Water Contact} Angle (WCA). The water vapor permeability of the composite films was assessed gravimetrically by using the ASTM E96-95 standard method [25]. Square film samples $(7.5 \mathrm{~cm} \times 7.5 \mathrm{~cm})$ were mounted in the water vapor permeability measuring cups filled with $18 \mathrm{~mL}$ of distilled water underneath the film. The cups were placed in the humidity chamber at $25^{\circ} \mathrm{C}$ and $50 \% \mathrm{RH}$. Then, each cup was weighed every hour for an $8 \mathrm{~h}$ period. The WVP (g.m/m $/ \mathrm{m}^{2}$.Pa.s) of the composite films was calculated per the following equation:

$$
\mathrm{WVP}=\frac{(\mathrm{WVTR} \times L)}{\Delta p},
$$

where WVTR was the measured water vapor transmission rate $\left(\mathrm{g} / \mathrm{m}^{2} . \mathrm{s}\right)$ through a film, $L$ was the mean film thickness $(m)$, and $\triangle p$ was the partial water vapor pressure difference $(\mathrm{Pa})$ across the two sides of the film.

The surface wettability of the composite films was analyzed using a WCA analyzer (Phoneix 150, Surface Electro Optics Co., Ltd., Kunpo, Korea) to determine its hydrophilicity/hydrophobicity. For this, each film was cut into rectangular strips $(3 \mathrm{~cm} \times 10 \mathrm{~cm})$ and placed on the horizontal movable Teflon-coated steel plate $(7 \times 11 \mathrm{~cm})$. A microsyringe was used to drop $10 \mu \mathrm{L}$ of water on the surface of the composite film, and the contact angle was analyzed on both sides of the water drop.

2.7.3. Thermal Stability. The thermal stability of the composite films was measured using a thermogravimetric analyzer (TGA; Hi-Res TGA 2950, TA Instrument, New Castle, DE, USA). For this, $5 \mathrm{mg}$ of each film was taken in a standard aluminum cup and heated from room temperature to $600^{\circ} \mathrm{C}$ under a nitrogen atmosphere at a flow rate of $50 \mathrm{~cm}^{3} / \mathrm{min}$. The temperature-dependent weight loss (\%) was recorded to plot the TGA curve, and the maximum decomposition temperature was determined from the derivative form of TGA (DTG) curves.

2.7.4. Thickness and Mechanical Properties. The thickness of the composite films was measured using a digital micrometer (Digimatic Micrometer, QuantuMike IP65, Mitutoyo, Japan) with an accuracy of $0.001 \mathrm{~mm}$. The measurements were carried out at least six random locations on each film sample, and the mean values were calculated.

Tensile properties of the composite films were analyzed using an Instron Universal Testing Machine (Model 5565, Instron Engineering Corporation, Canton, MA, USA). Tensile strength (TS), elongation at break (EB), and elastic modulus (EM) of composite films were measured according 
to the standard test method ASTM D882-88. The composite films were cut into rectangular shaped strips $(2.54 \mathrm{~cm} \times 15 \mathrm{~cm})$ by a precision double blade cutter (model LB.02/A, Metrotec, S.A., San Sebastian, Spain) and were stretched with an initial grip separation of $50 \mathrm{~mm}$ and a cross-head speed of $50 \mathrm{~mm} / \mathrm{min}$.

\subsection{Functional Properties of Carr/AgNP Nanocomposite Films}

\subsubsection{Antioxidant Activity}

(1) DPPH Radical Scavenging Assay. The DPPH radical scavenging activity of the films was measured using a DPPH (2, 2-diphenyl-1-CID="C014" value="picrylhydrazyl") free radical scavenging assay with slight modification [26]. For this, $100 \mathrm{mg}$ of each film sample was added to DPPH methanolic solution (prepared by adding $0.008 \mathrm{~g} \mathrm{DPPH}$ to $200 \mathrm{~mL}$ distilled water) and incubated in the dark for $30 \mathrm{~min}$ at $25^{\circ} \mathrm{C}$. Following this, the absorption was measured at $517 \mathrm{~nm}$ wavelength using a UV-vis spectrophotometer. The DPPH free radical scavenging activity of the films was determined as the percentage decrease in the absorbance of solution exposed to sample films compared to the blank sample according to the following equation:

$$
\text { DPPH scavenging }(\%)=\frac{\left(A_{\mathrm{DPPH}}-A_{\mathrm{film}}\right)}{A_{\mathrm{DPPH}}} \times 100 \text {, }
$$

where $A_{\mathrm{DPPH}}$ and $A_{\text {film }}$ were the absorbance values at $517 \mathrm{~nm}$ for the control DPPH solution and the DPPH solution exposed to film samples, respectively.

(2) ABTS Radical Scavenging Assay. ABTS radical scavenging activity was analyzed using the previously reported method with slight modification [27]. For preparing the ABTS radical solution, $100 \mathrm{~mL}$ of $2.5 \mathrm{mM}$ ABTS $\left(2,2^{\prime}\right.$ -azino-bis(3-ethyl-benzothiazoline-6CID="C015" value=""sulphonic acid)) solution was mixed with $100 \mathrm{~mL}$ of $1 \mathrm{mM}$ AAPH (2,2' -azobis(2-amidinopropane) dihydrochloride) solution and incubated in the dark for $30 \mathrm{~min}$ at $70^{\circ} \mathrm{C}$. Then, phosphate buffer saline was mixed to adjust the $\mathrm{pH}$ of the solution to 7.4. For the assay, $100 \mathrm{mg}$ of the sample film was added to $200 \mathrm{~mL}$ of ABTS solution and incubated in the dark for $30 \mathrm{~min}$. After that, the absorbance was analyzed using UV/Vis spectrophotometer at $734 \mathrm{~nm}$. The ABTS radical scavenging activity of the films was determined as a percentage decrease in absorbance of solution exposed to sample films compared to the blank sample according to the following equation:

$$
\operatorname{ABTS} \text { scavenging }(\%)=\frac{\left(A_{\mathrm{ABTS}}-A_{\mathrm{film}}\right)}{A_{\mathrm{ABTS}}} \times 100,
$$

where $A_{\mathrm{ABTS}}$ and $A_{\text {film }}$ were the absorbance values at $734 \mathrm{~nm}$ for the control ABTS solution and the ABTS solution exposed to film samples, respectively.
2.8.2. Antimicrobial Activity. The antimicrobial activity of nanocomposite films was tested with the slight modification of the previously reported method [5] against food-borne pathogenic Gram-positive S. aureus and Gram-negative E. coli O157: H7 bacteria. For this, the TSB broth inoculated with individual bacterial strains at an initial concentration of approximately 5-6 $\log \mathrm{CFU} / \mathrm{mL}$ was prepared. The bacterial broth was divided into several Erlenmeyer flasks with $20 \mathrm{~mL}$ volume in each one. After that, $100 \mathrm{mg}$ of different nanocomposite film samples were added to each flask and incubated at $37^{\circ} \mathrm{C}$ for $12 \mathrm{~h}$ in the incubator shaker, while the bacterial broth without any film was used as control. The cultures from each flask were inoculated onto freshly prepared TSB agar plates at regular intervals (i.e., 3, 6, 9, and $12 \mathrm{~h}$ ). The inoculated plates were incubated at $37^{\circ} \mathrm{C}$ for $18 \mathrm{~h}$, after which the bacterial colonies were counted, and the results were presented in Log CFU/mL. The test was carried out in triplicates for each film sample.

2.9. Statistical Analysis. For each film, the optical properties, surface color, antioxidant activity, antimicrobial activity, and WVP were studied in triplicates, and five replications for mechanical properties and WCA were performed, and the results were reported as mean $\pm \mathrm{SD}$ (standard deviation). One-way analysis of variance (ANOVA) was conducted, and the significance of each mean value was determined $(p<0.05)$ with Duncan's multiple range test using SPSS (SPSS Inc., Chicago, IL, USA).

\section{Results and Discussion}

3.1. Characterization of AgNP. The morphology of AgNP was observed by the FE-SEM, which revealed a nearly spherical shape of the particles (Figure 1(a)). The particle size was uniform with a mean diameter of $63.9 \pm 2.1 \mathrm{~nm}$. FT-IR spectra of pine needle extract and AgNP are shown in Figure 1(b). The pine needle displayed absorption bands at $3272 \mathrm{~cm}^{-1}$ corresponding to hydroxyl groups [28] and 2919 and $2850 \mathrm{~cm}^{-1}$ due to the $\mathrm{C}-\mathrm{H}$ stretch of the alkane group [29]. The absorption band at $1695 \mathrm{~cm}^{-1}$ was assigned to the ester bond $(-\mathrm{C}=\mathrm{O})$ [30], while the one at $1606 \mathrm{~cm}^{-1}$ was due to $C=C$ aromatic skeletal vibration [31]. The $1373 \mathrm{~cm}^{-1}$ absorption band was assigned to the indole ring vibration [32], while the $1238 \mathrm{~cm}^{-1}$ band was due to $-\mathrm{C}-\mathrm{O}$ and $-\mathrm{CH}_{2}$ [30]. A band at $1027 \mathrm{~cm}^{-1}$ corresponded to $-\mathrm{C}-\mathrm{O}$, and the one obtained at $718 \mathrm{~cm}^{-1}$ was assigned to the $-\left(\mathrm{CH}_{2}\right)_{\mathrm{n}^{-}}$and $-\mathrm{HC}=\mathrm{CH}$-(cis) [30]. For the spectra of AgNP, similar lowintensity peaks were obtained. The $3321 \mathrm{~cm}^{-1}$ absorption band corresponded to the hydroxyl stretching, while the bands at 2919 and $2850 \mathrm{~cm}^{-1}$ corresponding to the $\mathrm{C}-\mathrm{H}$ stretch of the alkane group were also apparent. Peaks at $1732 \mathrm{~cm}^{-1}$ in AgNP were assigned to ester bond $(-\mathrm{C}=\mathrm{O})$ while that at $1634 \mathrm{~cm}^{-1}$ was due to $\mathrm{C}=\mathrm{C}$ aromatic skeletal vibration. The shifting in the peak positions in AgNP represents the interaction between pine needle extract and AgNP. On the other hand, a new peak at $1171 \mathrm{~cm}^{-1}$ indicated carbonyl groups $(\mathrm{C}=\mathrm{O})$ [33]. The crystalline nature of the AgNP was analyzed using XRD analysis (Figure 1(c)). The XRD pattern exhibited diffraction peaks at (111), (200), 


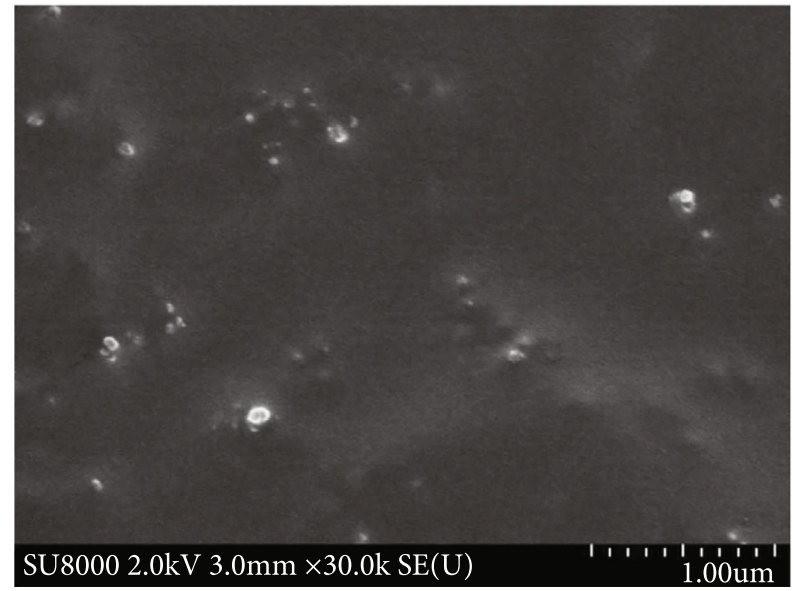

(a)

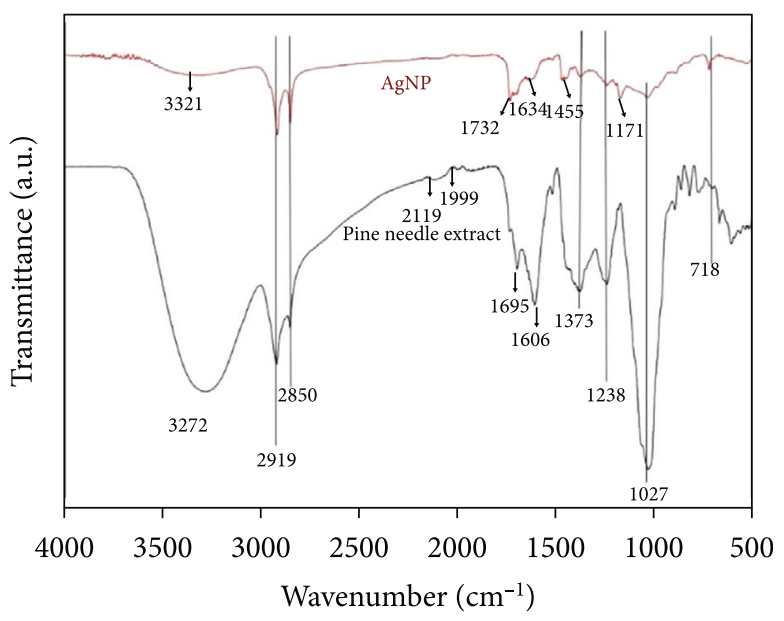

(b)

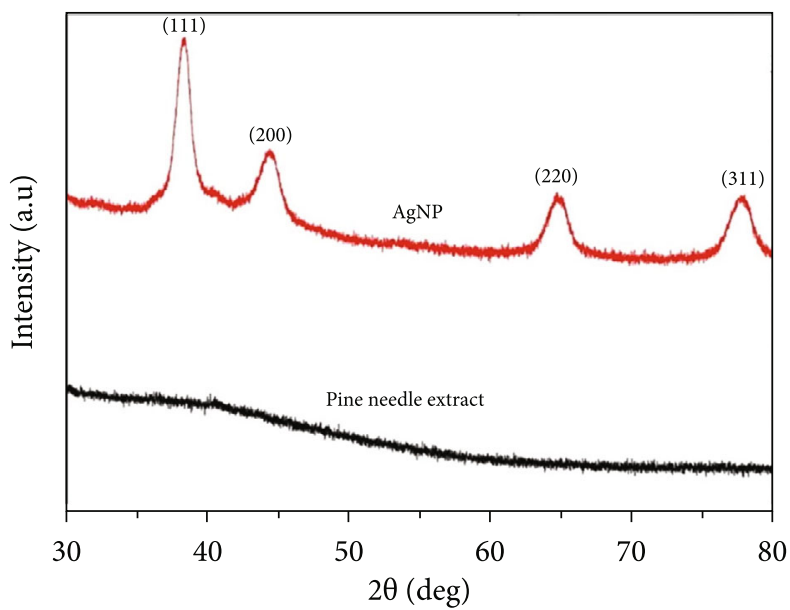

(c)

Figure 1: (a) FE-SEM micrograph of AgNP, (b) FT-IR spectra, and (c) XRD patterns of pine needle extract and AgNP.

(220), and (311) lattice planes which are characteristics of silver nanoparticles [12], determining the formation of crystalline AgNP. However, the pine needle extract did not show any diffraction peak indicating the amorphous nature of the capping polyphenols.

3.2. Characterization of Nanocomposite Films. The surface morphology of nanocomposite films was examined by FESEM (Figure 2). The surface of carrageenan film was smooth and compact, while nanocomposite films showed homogeneously distributed AgNP particles, thus increasing the roughness of the film surface. Similar morphological results and enhanced roughness with nanoparticle incorporation were observed in the previous studies [5, 34, 35].

X-ray diffraction (XRD) patterns of the Carr and Carr/ AgNP composite films are presented in Figure 3(a). The characteristic peaks of silver nanoparticles corresponding to (111), (220), and (311) lattice planes appeared in the XRD spectra of the nanocomposite films [36], indicating successful and homogeneous incorporation of AgNP in carrageenan films. The low intensity of the peaks is attributed to the minute concentration of nanofillers compared to the polymer matrix material.

FT-IR analysis was carried out to determine the structural changes in the carrageenan matrix on the incorporation of AgNP and ascertain the interaction between the matrix and the filler (Figure 3(b)). The results indicate no considerable change in the structure of the films on AgNP addition. The spectrum of carrageenan showed various characteristic peaks in the range of $4000 \mathrm{~cm}^{-1}$ to $500 \mathrm{~cm}^{-}$ 1 . The broad absorption band at about $3332 \mathrm{~cm}^{-1}$ indicated stretching of hydroxyl $(\mathrm{O}-\mathrm{H})$ groups [28]. The bands observed at 2928 and $2889 \mathrm{~cm}^{-1}$ corresponded to $\mathrm{C}-\mathrm{H}$ stretching vibrations of the alkane group [5]. The intense peak at $1635 \mathrm{~cm}^{-1}$ indicated the typical amide-I vibrations [37]. The absorption band corresponding to the sulfate ester groups in carrageenan was obtained at $1219 \mathrm{~cm}^{-1}$ [38]. The 1154 and $1068 \mathrm{~cm}^{-1}$ bands indicated stretching of the ester group $(\mathrm{C}=\mathrm{O})$. The characteristic absorption band at $913 \mathrm{~cm}^{-1}$ was due to the 3,6-anhydro-D-galactose [7], while the one observed at $841 \mathrm{~cm}^{-1}$ corresponded to galactose-4sulfate [39]. The addition of AgNPs did not show significant 


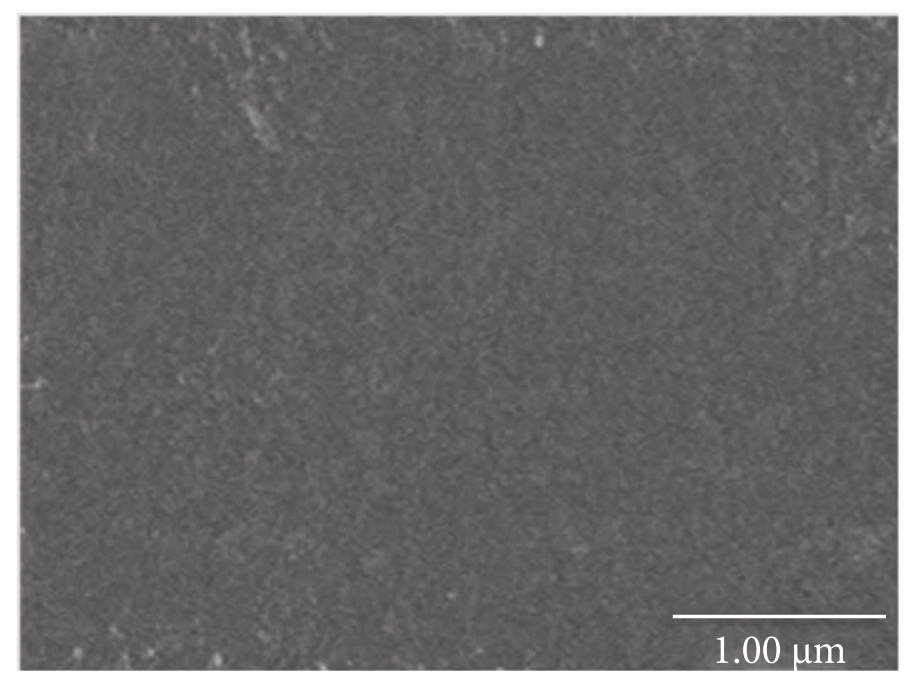

(a)

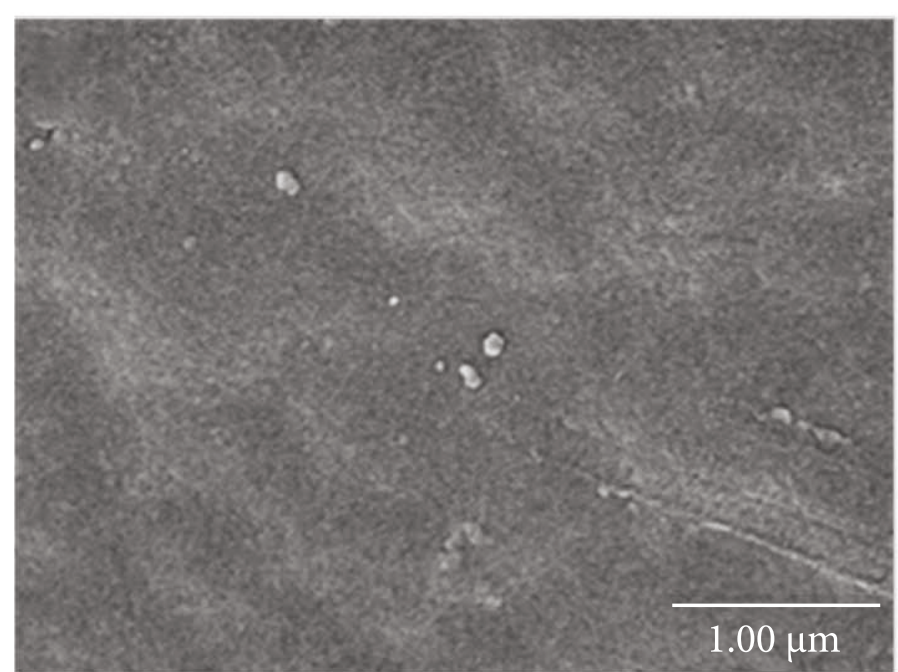

(b)

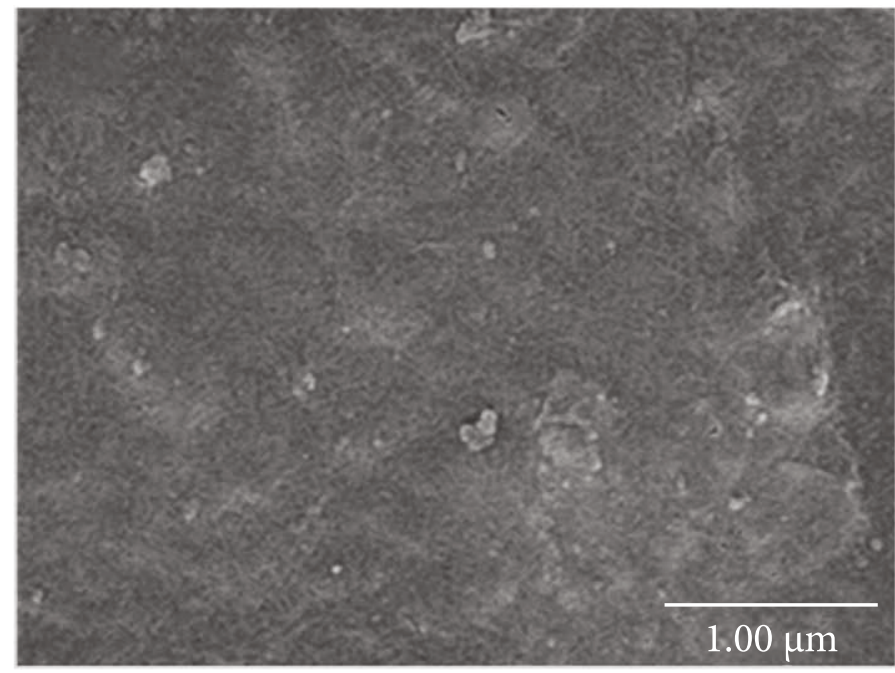

(c)

Figure 2: Continued. 


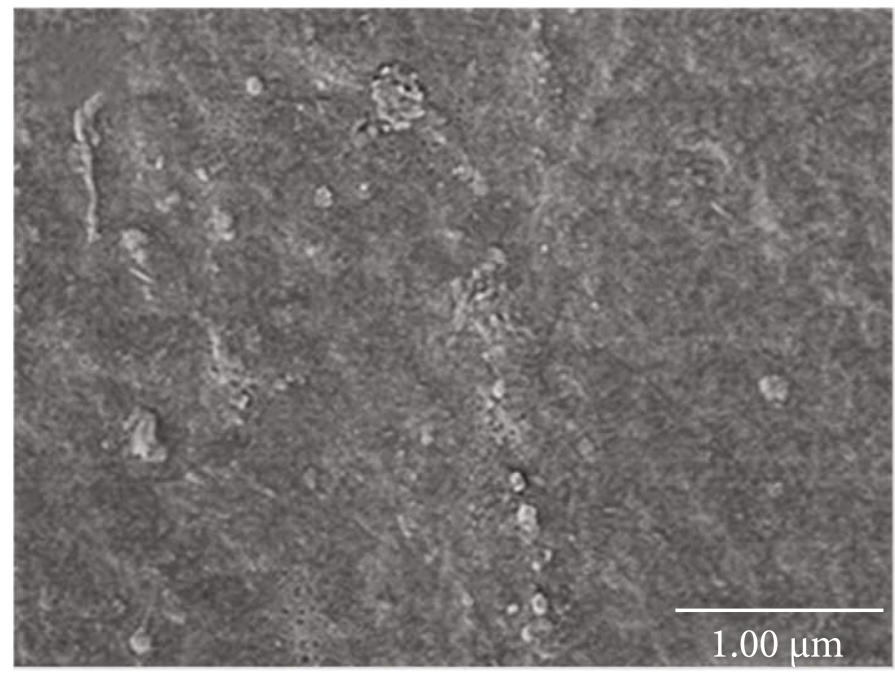

(d)

Figure 2: FE-SEM micrographs of Carr/AgNP nanocomposite films; (a) Carr, (b) Carr/AgNP ${ }^{1 \%}$, (c) Carr/AgNP ${ }^{2 \%}$, and (d) Carr/AgNP ${ }^{3 \%}$.

changes in functional groups and band positions [5]. However, the intensity of bands at 1635,1219 , and $1068 \mathrm{~cm}^{-1}$ in nanocomposite films was observed to be significantly higher than those in the neat Carr films, which is due to the pine needle extract polyphenols present in the AgNP nanofillers, as observed from the FT-IR spectra of the pine needle extract (Figure 1(b)).

\subsection{Physicochemical Properties of Nanocomposite Films}

3.3.1. Optical and Color Properties. The surface color values of the carrageenan-based films are shown in Table 1. The incorporation of AgNP affected the color properties of the nanocomposite films. The brightness $(L *)$ significantly decreased with the incorporation of nanofillers which offered a darker shade to the films. At a $3 \%$ concentration of $\mathrm{AgNP}$, the $L *$ value dropped down to 46.2 compared to 91.2 for neat films, which indicates a $49 \%$ decrease in brightness. Also, the redness values $(a *)$ were increased significantly from -0.5 for the neat film to +17.9 on the addition of $3 \mathrm{wt} \%$ AgNP into Carr films $(p<0.05)$, indicating the change in color from slightly greenish to moderately reddish shade. The yellowness value $(b *)$ for Carr was 5.2 , which increased to 39.1 for Carr/AgNP ${ }^{1 \%}$, indicating a humongous $650 \%$ increase in the yellowness of the films. However, with a further increase in AgNP concentration, the yellowness again decreased to 21.1 for Carr $/ \mathrm{AgNP}^{3 \%}$. The total color difference $(\triangle E)$ of nanocomposite films increased significantly $(p<0.05)$ from $1.5 \pm 0.1$ to $51.4 \pm 0.3$ after blending with AgNP. Similar results were reported in previous research as well [5].

The light absorption spectra of the nanocomposite films in the 200-800 $\mathrm{nm}$ range are shown in Figure 4. The carrageenan film did not show any radiation absorption within a scanned wavelength, while AgNP incorporated carrageenan films absorbed the radiations in the near and far UV regions, and around $430-480 \mathrm{~nm}$ is the characteristic absorption region of the silver nanoparticles. The intensity of the 430-480 $\mathrm{nm}$ absorption peak increased with the concentration of the AgNP. It was reported that AgNP absorbed radiations at $410-430 \mathrm{~nm}[11,12,36,40]$. Overall, despite being less transparent than Carr films, the nanocomposite films showed decent light transmittance in the visible region of the spectrum.

The percent transmittance of UV radiations $\left(T_{280}\right)$ and visible light $\left(T_{660}\right)$ was analyzed, and the results are shown in Table 1. The transmittance values at both $280 \mathrm{~nm}$ and $660 \mathrm{~nm}\left(T_{280}\right.$ and $T_{660}$, respectively) decreased by the addition of AgNP $(p<0.05)$. Although the neat Carr film was highly permeable to UV radiations, with a transmittance value of $74.8 \pm 1.3 \%$, the Carr/AgNP ${ }^{3 \%}$ films absorbed 99.5 $\pm 0.1 \%$ of the UV light, indicating negligible transmittance, which indicated the excellent UV-blocking effect of AgNP in the films. However, the transmittance values in the visible region $\left(T_{660}\right)$ were also significantly $(p<0.05)$ decreased from $90.7 \pm 0.5 \%$ to $26.6 \pm 2.9 \%$ with an increase in AgNP concentration in the films, indicating around $70 \%$ reduction in transparency. Therefore, Carr/AgNP films with strong UV and visible light blocking capacity are expected to be used as food packaging materials easily photooxidized food products.

3.3.2. Thermal Property. The thermal stability of nanocomposite films was evaluated by thermogravimetric analysis (TGA) (Figure 5). The TGA represents the temperaturedependent weight loss (\%) of the films indicating their thermal degradation. In contrast, the DTG provides information about the maximum degradation temperature at each thermal decomposition step. As shown in Figure 4, the films displayed a 2-step thermal degradation pattern. The first step degradation occurred below $100^{\circ} \mathrm{C}$, attributed to the loss of moisture [41], while the second step degradation occurred around $230^{\circ} \mathrm{C}$, indicating the evaporation of glycerol and polymer chain degradation [3]. Even though no considerable difference in the thermal degradation pattern of nanocomposite films was observed compared to the 


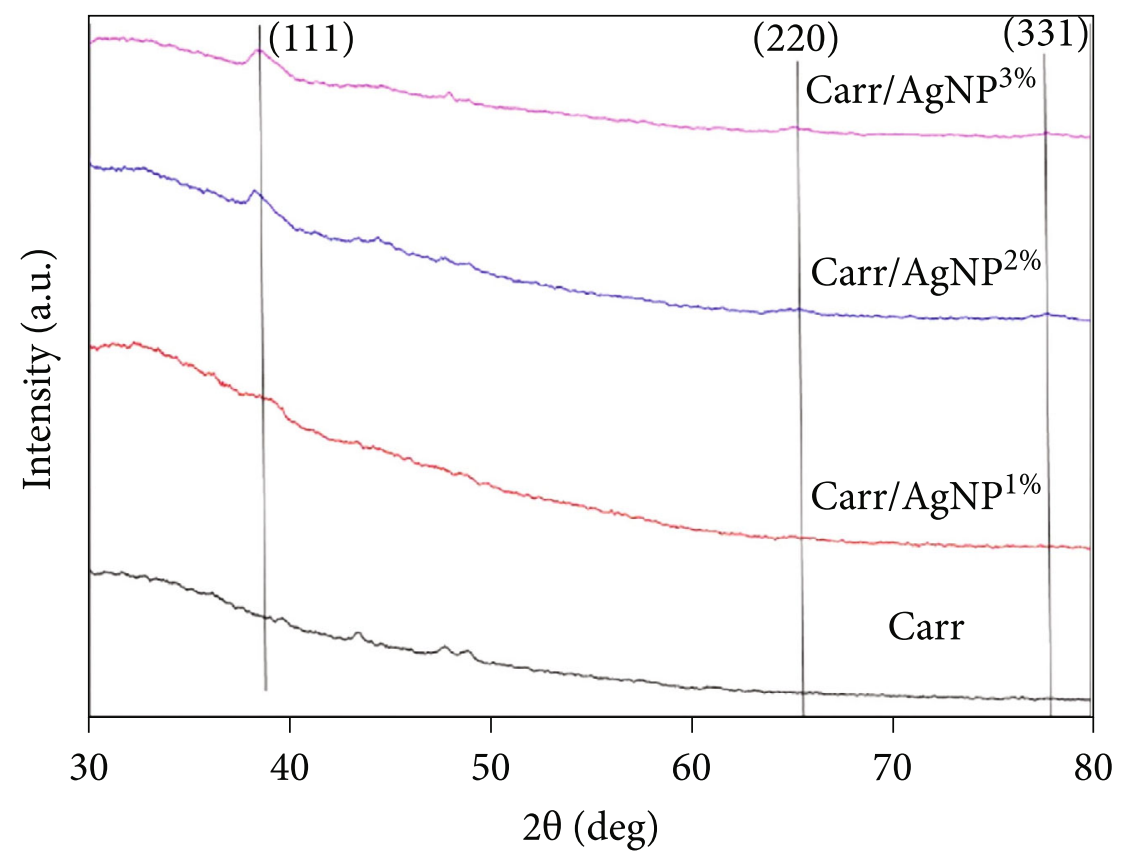

(a)

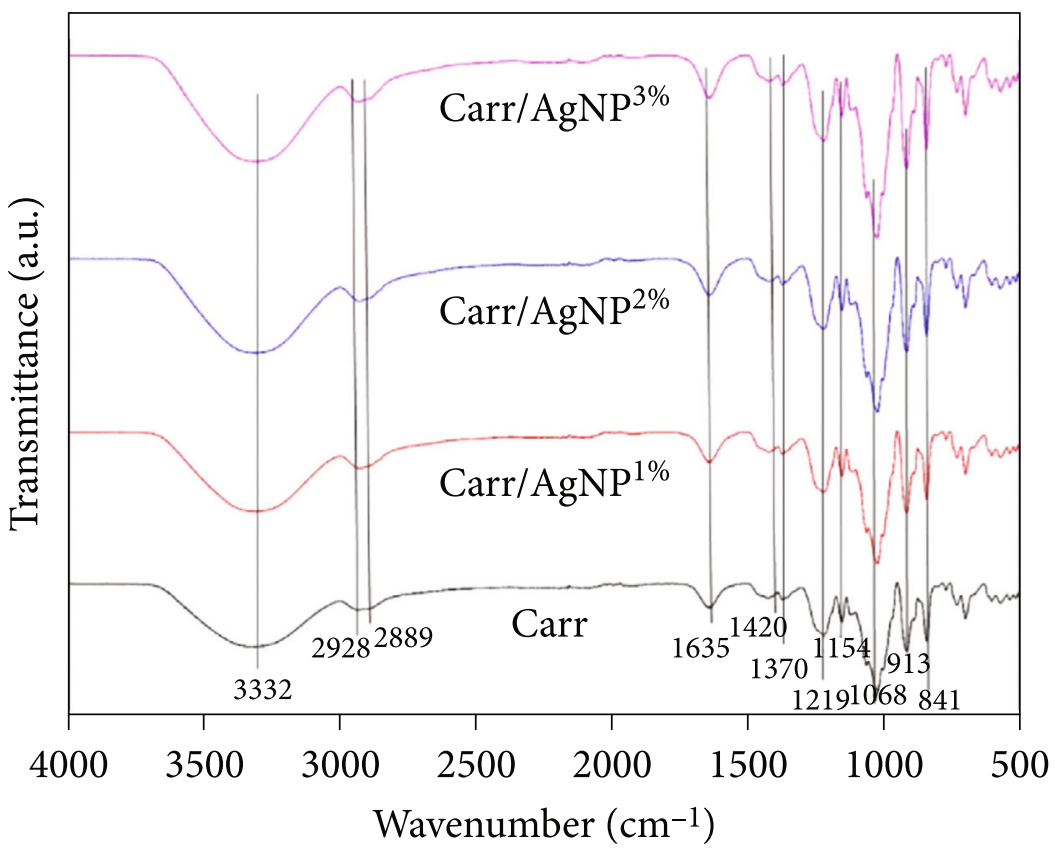

(b)

FIGURE 3: (a) XRD and (b) FT-IR spectra of Carr/AgNP nanocomposite films.

TABLE 1: Surface color and transmittance of Carr/AgNP nanocomposite films.

\begin{tabular}{lcccccc}
\hline Film & $L *$ & $a *$ & $b *$ & $\Delta E$ & $T_{280}$ & $T_{660}$ \\
\hline Carr & $91.2 \pm 0.1^{\mathrm{a}}$ & $-0.5 \pm 0.1^{\mathrm{a}}$ & $5.2 \pm 0.1^{\mathrm{a}}$ & $1.5 \pm 0.1^{\mathrm{a}}$ & $74.8 \pm 1.3^{\mathrm{a}}$ & $90.7 \pm 0.5^{\mathrm{a}}$ \\
Carr/AgNP ${ }^{1 \%}$ & $62.8 \pm 1.4^{\mathrm{b}}$ & $12.7 \pm 0.8^{\mathrm{b}}$ & $39.1 \pm 0.4^{\mathrm{b}}$ & $47.1 \pm 1.3^{\mathrm{b}}$ & $1.0 \pm 0.3^{\mathrm{b}}$ & $50.0 \pm 1.8^{\mathrm{b}}$ \\
Carr/AgNP $^{2 \%}$ & $47.9 \pm 1.7^{\mathrm{c}}$ & $15.9 \pm 1.2^{\mathrm{c}}$ & $22.6 \pm 0.4^{\mathrm{c}}$ & $51.0 \pm 1.5^{\mathrm{c}}$ & $0.5 \pm 0.3^{\mathrm{b}}$ & $48.4 \pm 0.1^{\mathrm{b}}$ \\
Carr/AgNP $^{3 \%}$ & $46.2 \pm 1.1^{\mathrm{c}}$ & $17.9 \pm 0.4^{\mathrm{d}}$ & $21.1 \pm 1.6^{\mathrm{c}}$ & $51.4 \pm 0.3^{\mathrm{c}}$ & $0.5 \pm 0.1^{\mathrm{b}}$ & $26.6 \pm 2.9^{\mathrm{c}}$ \\
\hline
\end{tabular}

The values are written as a mean \pm standard deviation. Different letters within the same column indicate significant differences $(p<0.05)$. 

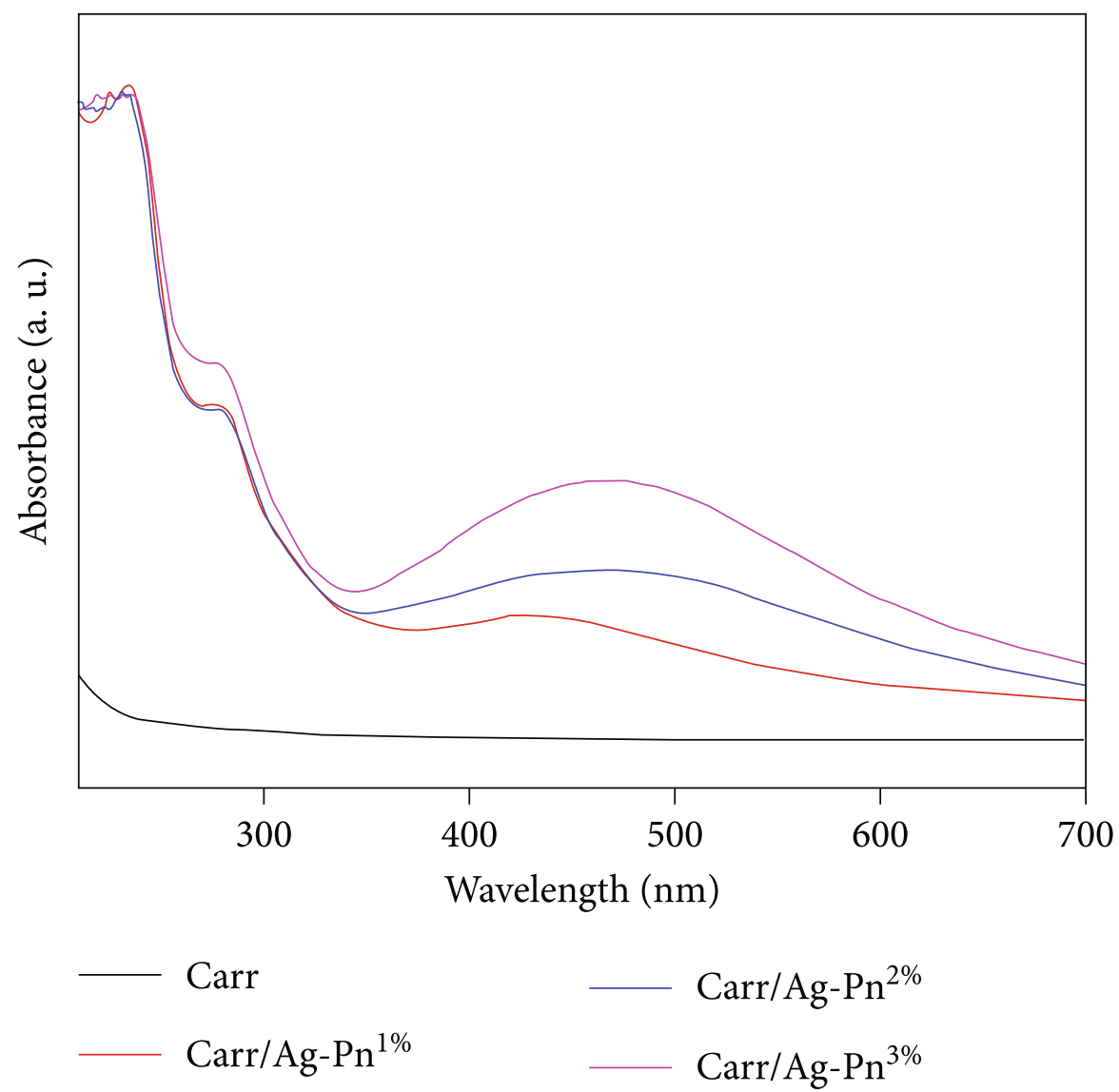

FIgURE 4: UV-visible absorption spectra of Carr/AgNP nanocomposite films.

neat Carr films, AgNPs incorporation slightly enhanced the thermal properties of the films. As observed from the DTG pattern, the addition of $1 \mathrm{wt} \%$ AgNP nanofillers increased the moisture content in the films as a higher weight loss was observed during the first degradation step. This may be the presence of various hydrophilic compounds in pine needle extract, such as polyphenols, sugar, and pectin, which bind the moisture. However, as the concentration of nanofillers increased further, the moisture content decreased. This may be attributed to the H-bonding between the hydroxyl groups of Ag-capping polyphenols of pine needle extract with the hydroxyl groups of the polymer, thus making them less available for moisture [42]. This interaction was confirmed by the FT-IR results, where the shifting of peaks was observed (Figure 3(b)). Also, a higher filler amount resulted in the occupation of interchain spaces, resulting in a blocked path for the ambient water molecules to enter the films. Nevertheless, no noteworthy changes were observed in the second step decomposition pattern of the films.

3.3.3. Water Vapor Permeability (WVP) and Water Contact Angle (WCA). The water vapor barrier property of the nanocomposite films was estimated by measuring the permeability of water vapor through the films (Table 2). The WVP of the nanocomposite films significantly increased with increasing AgNP concentration compared with the neat Carr film. This can be explained by increased interchain spacing when AgNP is incorporated in the films, making the passage of water molecules easier through the films. Even though there are reports where nanofiller incorporation created a tortuous path for the water molecules creating an opposite effect, the nanofillers under consideration were nonhydrophilic [43]. However, in the present case, the polyphenolic capping on the nanoparticles provided hydroxyl groups for the water molecules, thus facilitating their adsorption and desorption through the polymer matrix with ease. Similar trends were observed for carrageenan films incorporated with melanin-mediated silver nanoparticles and the agar/AgNP nanocomposite films, showing that the WVP increased by increasing AgNP concentration $[5,44]$. However, the WVP of gelatin film incorporated AgNP was not changed [36]. The results indicate that the WVP depends on the types of the polymer matrix and the type of nanofiller and the concentration of nanoparticles [5].

The water contact angle (WCA) analysis of the film samples is also shown in Table 2. The WCA helps determine the hydrophobicity or hydrophilicity on the surface of the films [45]. The WCA value of the control film was $62.9 \pm 3.9^{\circ}$, and the values significantly increased by the addition of AgNP in Carr film. This can again be explained by the presence of hydroxyl groups on polyphenol capped nanoparticles that interact with the polymer matrix's hydroxyl groups by $\mathrm{H}$ bonding [42]. In this way, the excess hydroxyl groups on the film surface become unavailable to the water molecules 


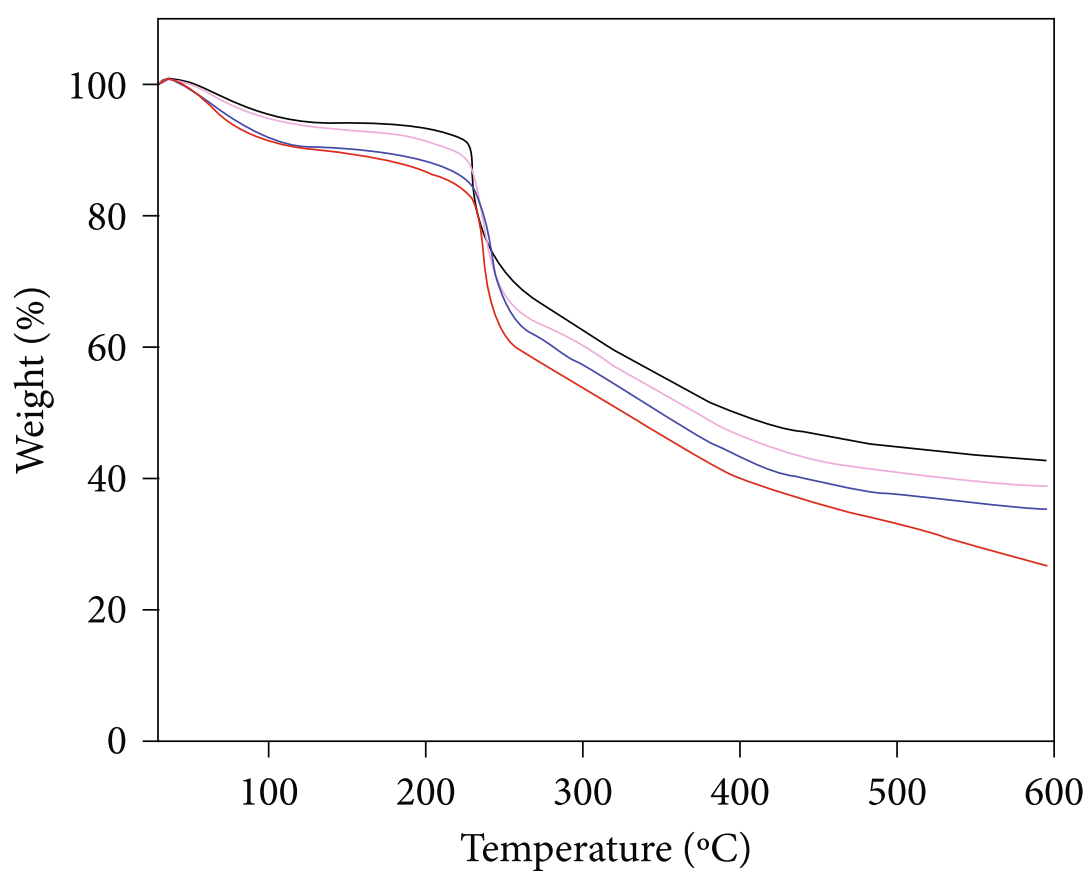

(a)
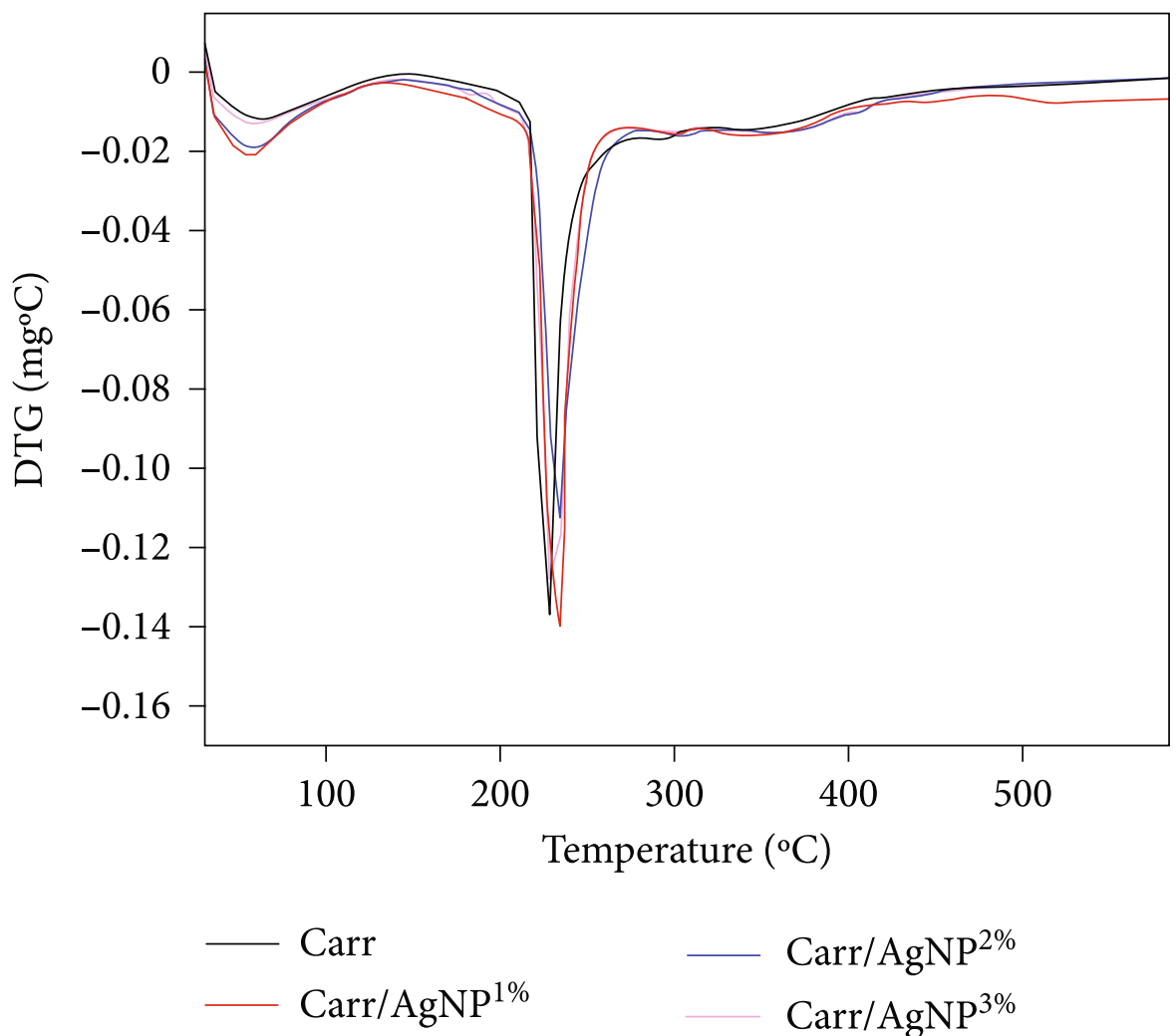

(b)

Figure 5: (a) TGA and (b) DTG thermograms of Carr/AgNP nanocomposite films.

resulting in decreased interaction between film surface and water. Since the WCA of the Carr film was $<65^{\circ}$, the film surface could be referred to as hydrophilic [46]. However, the values for all the nanocomposite films were $>65^{\circ}$. Hence, the Carr/AgNP can be considered hydrophobic.
3.3.4. Thickness and Mechanical Properties. The thickness and mechanical properties of nanocomposite films are shown in Table 2. The thickness of carrageenan film was $53.5 \mu \mathrm{m}$, which significantly increased on the addition of AgNP, where the incorporation of $1 \mathrm{wt} \%$ nanofillers resulted 
TABLE 2: Mechanical properties, water vapor permeability, and water contact angle of Carr/AgNP nanocomposite films.

\begin{tabular}{|c|c|c|c|c|c|c|}
\hline Film & Thickness $(\mu \mathrm{m})$ & $\mathrm{TS}(\mathrm{MPa})$ & $\mathrm{EB}(\%)$ & $\mathrm{EM}(\mathrm{GPa})$ & WVP $\left(\times 10^{-9}\right.$ g.m $/ \mathrm{m}^{2}$ Pa.s $)$ & $\operatorname{WCA}\left({ }^{\circ}\right)$ \\
\hline Carr & $53.5 \pm 0.1^{\mathrm{a}}$ & $30.2 \pm 1.8^{\mathrm{a}}$ & $21.8 \pm 1.8^{\mathrm{a}}$ & $1.07 \pm 0.09^{\mathrm{a}}$ & $0.98 \pm 0.03^{\mathrm{a}}$ & $62.9 \pm 3.9^{\mathrm{a}}$ \\
\hline Carr/AgNP ${ }^{1 \%}$ & $63.8 \pm 2.3^{b}$ & $43.6 \pm 3.4^{\mathrm{b}}$ & $14.8 \pm 2.9^{\mathrm{b}}$ & $1.11 \pm 0.02^{\mathrm{a}}$ & $1.31 \pm 0.04^{\mathrm{b}}$ & $67.5 \pm 1.2^{\mathrm{b}}$ \\
\hline Carr/AgNP ${ }^{2 \%}$ & $65.1 \pm 2.8^{\mathrm{b}}$ & $46.7 \pm 2.8^{\mathrm{b}}$ & $13.2 \pm 2.0^{\mathrm{b}}$ & $1.27 \pm 0.01^{\mathrm{b}}$ & $1.29 \pm 0.07^{\mathrm{b}}$ & $68.9 \pm 0.9^{\mathrm{b}}$ \\
\hline Carr/AgNP ${ }^{3 \%}$ & $66.8 \pm 3.7^{b}$ & $50.0 \pm 4.8^{\mathrm{b}}$ & $10.6 \pm 2.6^{\mathrm{b}}$ & $1.43 \pm 0.02^{\mathrm{c}}$ & $1.44 \pm 0.09^{\mathrm{c}}$ & $70.0 \pm 1.4^{\mathrm{b}}$ \\
\hline
\end{tabular}

The values are written as a mean \pm standard deviation. Different letters within the same column indicated significant differences $(p<0.05)$.

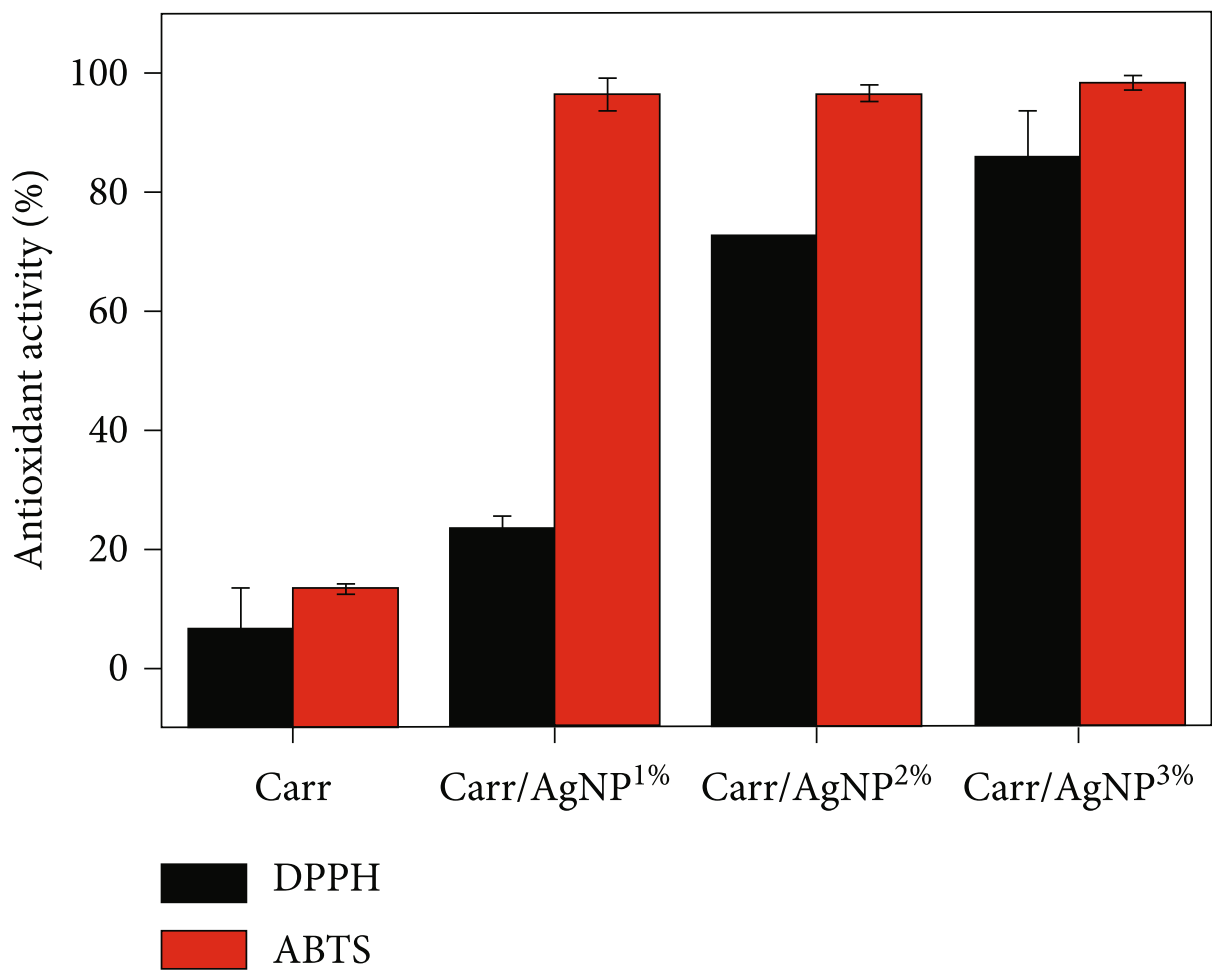

FIGURE 6: Antioxidant activity of Carr/AgNP nanocomposite films.

in around 19\% increment. Also, with increasing nanofiller concentration, the thickness increased further as expected, attributed to the increased solid content in the films [3]. Nevertheless, this increase with rising AgNP concentration was not statistically significant.

The mechanical properties of the nanocomposite films were estimated in terms of the tensile strength (TS), elongation at break (EB), and elastic modulus (EM) (Table 2). The Carr film displayed a TS of 30.2 MPa, which increased significantly $(p<0.05)$ with the incorporation of AgNP. For $3 \mathrm{wt} \%$ nanofiller addition, the TS value increased up to $50 \mathrm{MPa}$, corresponding to an almost $65 \%$ rise. The enhanced TS of the nanocomposite films results from the interaction between the polymer matrix and the nanofiller (Roy, Shankar \& Rhim, 2019). The FT-IR spectra provide evidence of hydrogen bonding between the nanofillers and the polymer matrix, which plays a considerable role in increasing the TS. Besides, this effect was also reported due to the straininduced alignment of filler particles which help in the uniform load dispersion throughout the polymer matrix [43].
The estimate of the flexibility and stiffness of the films was provided by EB and EM, respectively. The EB of Carr decreased from $21.8 \%$ for Carr to $10.6 \%$ for Carr/AgNP $3 \%$, which is consistent with the results reported previously. Further, the EM of the films displayed a 33\% enhancement with the incorporation of $3 \mathrm{wt} \%$ AgNP, indicating an increased stiffness. In general, adding nanofillers increases TS and EM but negatively affects EB values. Hence, with rising nanofiller concentration, the strength and stiffness values are increased, while the flexibility of the films is decreased.

\subsection{Functional Properties of Nanocomposite Films}

3.4.1. Antioxidant Activity. The antioxidant activities of Carr and Carr/AgNP composite films were determined by DPPH and ABTS radical scavenging activity (Figure 6). Negligible antioxidant activity was observed for the carrageenan films, which increased with the increasing concentration of AgNP. The ABTS radical scavenging activity of the nanocomposite films displayed a tremendous increase to reach almost $100 \%$ 


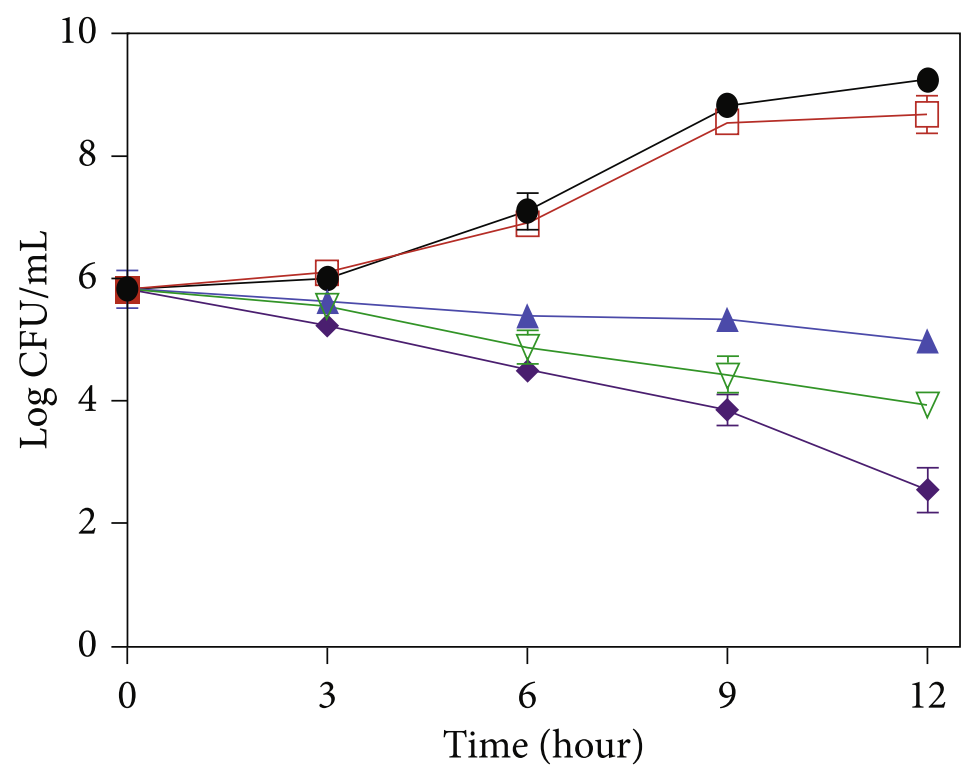

- Control
$\square$ Carr
- Carr/AgNP ${ }^{1 \%}$
$\nabla$ Carr/AgNP ${ }^{2 \%}$
- Carr/AgNP ${ }^{3 \%}$

(a)

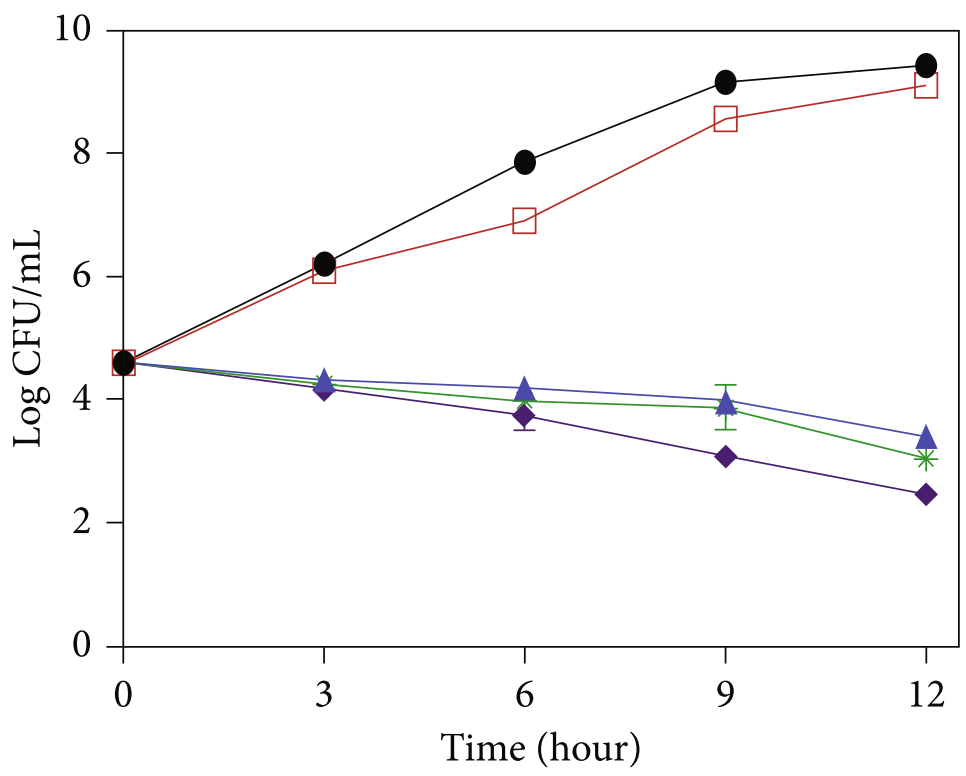

- - Control

$\square$ Carr

— Carr/ $/ \mathrm{AgNP}^{1 \%}$

* Carr/AgN2 ${ }^{2 \%}$

$\rightarrow$ Carr/AgNP ${ }^{3 \%}$

(b)

Figure 7: Antimicrobial activity of Carr/AgNP nanocomposite films against (a) Staphylococcus aureus and (b) E. coli O157: H7. 
even at the least nanofiller concentration (i.e., $1 \mathrm{wt} \%)$. On the other hand, the DPPH radical scavenging activity increased only up to a value of $25 \%$ at this concentration of AgNP, reaching a maximum value of $87 \%$ for Carr $/ \mathrm{AgNP}^{3 \%}$. The difference between DPPH and ABTS radical scavenging activities is attributed to the carrageenan films' hydrophilicity and the pine needle polyphenols responsible for the antioxidant activity $[47,48]$. The hydrophilicity leads to enhanced interaction of the polyphenols with the ABTS free radicals in aqueous solution than with DPPH free radicals in methanolic solution $[34,49]$. The results indicate the potential of Carr/AgNP nanocomposite films as active antioxidant packaging materials to extend shelf life and maintain the quality of food products prone to oxidative deterioration.

3.4.2. Antibacterial Activity. Antibacterial activity of the nanocomposite films was determined by time-kill assay against food-borne pathogenic bacteria Staphylococcus aureus (Gram-positive) and E. coli O157: H7 (Gram-negative), and the results are shown in Figure 7. The neat Carr film did not show significant antibacterial activity against both the bacterial strains, and the bacterial growth pattern was almost similar to the control group. The addition of AgNP nanofillers imparted antimicrobial properties to the films. However, the activity was not as strong as reported for silver nanoparticles [50]. Nanoparticles exert antimicrobial effect by the mechanism involving the production of reactive oxygen species (ROS), which interact with the bacterial cell wall, resulting in its degradation and disruption [51, 52]. Another possible mechanism is the formation of $\mathrm{Ag}^{+}$ ions, which electrostatically interact with the negatively charged molecules present on the bacterial cell wall [50]. Therefore, the low antimicrobial activity of AgNP is presumed to be the surface capping with polyphenols which may have reduced the electrostatic interaction of nanoparticles with the bacterial cells, and the residual antimicrobial effect is solely due to the ROS production. Nevertheless, the population of bacterial cells decreased with time, suggesting a bacteriostatic effect against both the bacterial strains. Further, the effect was slightly higher against $S$. aureus than $E$. coli, indicated by almost $3.5 \mathrm{Log} \mathrm{CFU} / \mathrm{mL}$ reduction against the Gram-positive strain compared to 2 Log CFU/mL reduction against the Gram-negative one, on exposure to Carr/AgNP ${ }^{3 \%}$. Hence, the films show great potential to be used as a food packaging material, especially in the form of hurdle technology with other food preservation methods, to prevent the microbial contamination of food products.

\section{Conclusions}

Silver nanoparticles were synthesized by a sustainable green synthesis method using pine needle extract as a reducing agent for reducing and capping agents. The pine needles are a renewable and abundant resource for functional polyphenols, which help in stabilizing the synthesized silver nanoparticles. Besides being used as capping and stabilizing agents, the pine needle polyphenols also imparted antioxidant potential to the AgNPs, making them multifunctional nanoparticles. The AgNPs were spherical with an average size of $63.9 \mathrm{~nm}$ and narrow size distribution. The XRD and FT-IR results confirmed the successful capping of Ag nanoparticles with pine needle polyphenols. When used as functional fillers in carrageenan-based films, the nanoparticles significantly affected the surface hydrophobicity and mechanical properties of the films. Besides, the nanoparticles imparted noticeable functional properties such as UV-blocking, antioxidant, and antimicrobial properties to carrageenan films. The Carr/AgNP ${ }^{3 \%}$ nanocomposite film exhibited nearly $100 \%$ UV protection and scavenged up to $87 \%$ of oxidative free radicals absent from the neat carrageenan film. The nanocomposite films also exhibited a decent antibacterial activity against both Gram-positive ( $S$. aureus) and Gram-negative (E. coli O157: H7) bacteria, reducing their population by almost 3.5 and 2 Log CFU/ $\mathrm{mL}$, respectively. These functional properties of nanocomposite films make them suitable for use as sustainable and biodegradable materials for active food packaging applications and are expected to extend the shelf life of packaged foods.

\section{Data Availability}

The data used to support the findings of this study are available from the corresponding author upon request.

\section{Conflicts of Interest}

The authors declare that they have no known competing financial interests or personal relationships that could have influenced the work reported in this paper.

\section{Acknowledgments}

This research was supported by the Brain Pool program funded by the Ministry of Science, ICT, and Future Planning through the National Research Foundation of Korea (2019H1D3A1A01070715) and the National Research Foundation of Korea (NRF) grant funded by the Korean government (MSIT) (No. 2019R1A2C2084221).

\section{References}

[1] R. Priyadarshi, B. Kumar, F. Deeba, A. Kulshreshtha, and Y. S. Negi, "Food packaging: natural and synthetic biopolymers," in Encycl. Polym. Appl, M. Mishra, Ed., pp. 1325-1342, First, Taylor and Francis Publishers, Boca Raton, 2019.

[2] R. Priyadarshi and J.-W. Rhim, "Chitosan-based biodegradable functional films for food packaging applications," Innovative Food Science and Emerging Technologies, vol. 62, p. 102346, 2020.

[3] S. Saedi, M. Shokri, R. Priyadarshi, and J.-W. Rhim, "Carrageenan-based antimicrobial films integrated with sulfurcoated iron oxide nanoparticles $\left(\mathrm{Fe}_{3} \mathrm{O}_{4} @ S N P\right), "$ ACS Applied Polymer Materials, vol. 3, no. 10, pp. 4913-4923, 2021.

[4] G. H. Therkelsen, "Carrageenan," in Ind Gums Polysaccharides Their Deriv. Third Ed, pp. 145-180, Elsevier Inc., 1993.

[5] S. Roy, S. Shankar, and J.-W. Rhim, "Melanin-mediated synthesis of silver nanoparticle and its use for the preparation of 
carrageenan-based antibacterial films," Food Hydrocolloids, vol. 88, pp. 237-246, 2019.

[6] S. Shojaee-Aliabadi, M. A. Mohammadifar, H. Hosseini et al., "Characterization of nanobiocomposite kappa-carrageenan film with _Zataria multiflora_ essential oil and nanoclay," International Journal of Biological Macromolecules, vol. 69, pp. 282-289, 2014.

[7] S. Saedi, M. Shokri, R. Priyadarshi, and J.-W. Rhim, "Silver ion loaded 3-aminopropyl trimethoxysilane -modified $\mathrm{Fe}_{3} \mathrm{O}_{4}$ nanoparticles for the fabrication of carrageenan-based active packaging films," Colloids and Surfaces. B, Biointerfaces, vol. 208, p. 112085, 2021.

[8] S. Shankar and J. W. Rhim, "Effect of types of zinc oxide nanoparticles on structural, mechanical and antibacterial properties of poly(lactide)/poly(butylene adipate-co-terephthalate) composite films," Food Packaging and Shelf Life, vol. 21, p. 100327, 2019.

[9] Y. Sun and Y. Xia, "Shape-controlled synthesis of gold and silver nanoparticles," Science, vol. 298, no. 5601, pp. 2176-2179, 2002.

[10] S. Shankar, R. Pangeni, J. W. Park, and J.-W. Rhim, "Preparation of sulfur nanoparticles and their antibacterial activity and cytotoxic effect," Materials Science and Engineering: C, vol. 92, pp. 508-517, 2018.

[11] R. K. Sharma, S. Tahiliani, N. Jain et al., "Cynodon dactylon leaf extract assisted green synthesis of silver nanoparticles and their anti-microbial activity," Advanced Science, Engineering and Medicine, vol. 5, no. 8, pp. 858-863, 2013.

[12] R. Priyadarshi and Y. S. Negi, "Poly(vinyl pyrrolidone)-mediated synthesis of silver nanowires decorated with silver nanospheres and their antimicrobial activity," Bulletin of Materials Science, vol. 42, no. 3, p. 118, 2019.

[13] S. Shankar, D. Khodaei, and M. Lacroix, "Effect of chitosan/ essential oils/silver nanoparticles composite films packaging and gamma irradiation on shelf life of strawberries," Food Hydrocolloids, vol. 117, p. 106750, 2021.

[14] N. Ardjoum, S. Shankar, N. Chibani, S. Salmieri, and M. Lacroix, "_In situ_synthesis of silver nanoparticles in pectin matrix using gamma irradiation for the preparation of antibacterial pectin/silver nanoparticles composite films," Food Hydrocolloids, vol. 121, p. 107000, 2021.

[15] K. N. Thakkar, S. S. Mhatre, and R. Y. Parikh, "Biological synthesis of metallic nanoparticles," Biologie et Médecine, vol. 6, no. 2, pp. 257-262, 2010.

[16] V. Dhand, L. Soumya, S. Bharadwaj, S. Chakra, D. Bhatt, and B. Sreedhar, "Green synthesis of silver nanoparticles using _Coffea arabica_ seed extract and its antibacterial activity," Materials Science and Engineering: C, vol. 58, pp. 36-43, 2016.

[17] R. A. Ismail, G. M. Sulaiman, M. H. Mohsin, and A. H. Saadoon, "Preparation of silver iodide nanoparticles using laser ablation in liquid for antibacterial applications," IET Nanobiotechnology, vol. 12, no. 6, pp. 781-786, 2018.

[18] K. M. M. Abou El-Nour, A. Eftaiha, A. Al-Warthan, and R. A. A. Ammar, "Synthesis and applications of silver nanoparticles," Arabian Journal of Chemistry, vol. 3, no. 3, pp. 135140, 2010.

[19] S. Azizi, R. Mohamad, R. Abdul Rahim, R. Mohammadinejad, and A. Bin Ariff, "Hydrogel beads bio-nanocomposite based on _Kappa-Carrageenan_ and green synthesized silver nanoparticles for biomedical applications," International Journal of Biological Macromolecules, vol. 104, no. Part A, pp. 423431, 2017.

[20] M. S. Jabir, A. A. Hussien, G. M. Sulaiman et al., "Green synthesis of silver nanoparticles from Eriobotrya japonica extract: a promising approach against cancer cells proliferation, inflammation, allergic disorders and phagocytosis inductionvol. 49, no. 1, pp. 48-60.

[21] Y. S. Park, M. H. Jeon, H. J. Hwang et al., "Antioxidant activity and analysis of proanthocyanidins from pine (Pinus densiflora) needles," Nutrition Research and Practice, vol. 5, no. 4, pp. 281-287, 2011.

[22] J.-R. Jeon, J.-Y. Kim, K.-M. Lee, and D.-H. Cho, “Anti-obese effects of mixture contained pine needle, black tea and green tea extracts," Applied Biological Chemistry, vol. 48, pp. $375-$ $381,2000$.

[23] T. Venkatesan, Y. W. Choi, and Y. K. Kim, "Effect of an extraction solvent on the antioxidant quality of _Pinus densiflora needle extract," Journal of Pharmaceutical Chemistry and Analysis, vol. 9, no. 3, pp. 193-200, 2019.

[24] S.-H. Park, K.-B.-W.-R. Kim, M.-J. Kim, J.-S. Choi, Y.-J. Cho, and D.-H. Ahn, "Antimicrobial activity of extracts from different parts and essential oil from Pinus densiflora on skin pathogens," Journal of Life Science, vol. 27, pp. 646-651, 2017.

[25] R. Priyadarshi, H.-J. Kim, and J.-W. Rhim, "Effect of sulfur nanoparticles on properties of alginate-based films for active food packaging applications," Food Hydrocolloids, vol. 110, p. 106155, 2021.

[26] A. Orsuwan, S. Shankar, L. F. Wang, R. Sothornvit, and J. W. Rhim, "Preparation of antimicrobial agar/banana powder blend films reinforced with silver nanoparticles," Food Hydrocolloids, vol. 60, pp. 476-485, 2016.

[27] S. Shankar, L. F. Wang, and J. W. Rhim, "Effect of melanin nanoparticles on the mechanical, water vapor barrier, and antioxidant properties of gelatin-based films for food packaging application," Food Packaging and Shelf Life, vol. 21, p. 100363, 2019.

[28] Y. Wu, F. Geng, P. R. Chang, J. Yu, and X. Ma, "Effect of agar on the microstructure and performance of potato starch film," Carbohydrate Polymers, vol. 76, no. 2, pp. 299-304, 2009.

[29] S. Roy and J. W. Rhim, "Melanin-mediated synthesis of copper oxide nanoparticles and preparation of functional agar/CuO NP nanocomposite films," Journal of Nanomaterials, vol. 2019, 10 pages, 2019.

[30] D. Atek and N. Belhaneche-Bensemra, "FTIR investigation of the specific migration of additives from rigid poly(vinyl chloride)," European Polymer Journal, vol. 41, no. 4, pp. 707-714, 2005.

[31] X. Zhao, J. Chen, F. Chen, X. Wang, Q. Zhu, and Q. Ao, "Surface characterization of corn stalk superfine powder studied by FTIR and XRD," Colloids and Surfaces. B, Biointerfaces, vol. 104, pp. 207-212, 2013.

[32] A. Mbonyiryivuze, B. Mwakikunga, S. M. Dhlamini, and M. Maaza, "Fourier transform infrared spectroscopy for sepia melanin," Physics and Materials Chemistry, vol. 3, pp. 25-29, 2015.

[33] D. Guille and N. Cabo, "Infrared spectroscopy in the study of edible oils and fats," Journal of the Science of Food and Agriculture, vol. 75, no. 1, pp. 1-11, 1997.

[34] R. Priyadarshi, S.-M. Kim, and J.-W. Rhim, "Carboxymethyl cellulose-based multifunctional film combined with zinc oxide nanoparticles and grape seed extract for the preservation of 
high-fat meat products," Sustainable Materials and Technologies, vol. 29, article e00325, 2021.

[35] Z. Riahi, R. Priyadarshi, J.-W. Rhim, and R. Bagheri, "Gelatinbased functional films integrated with grapefruit seed extract and $\mathrm{TiO}_{2}$ for active food packaging applications," Food Hydrocolloids, vol. 112, p. 106314, 2021.

[36] P. Kanmani and J. W. Rhim, "Physicochemical properties of gelatin/silver nanoparticle antimicrobial composite films," Food Chemistry, vol. 148, pp. 162-169, 2014.

[37] H. Hezaveh and I. I. Muhamad, "Modification and swelling kinetic study of kappa-carrageenan-based hydrogel for controlled release study," Journal of the Taiwan Institute of Chemical Engineers, vol. 44, no. 2, pp. 182-191, 2013.

[38] L. Pereira, A. M. Amado, A. T. Critchley, F. van de Velde, and P. J. A. Ribeiro-Claro, "Identification of selected seaweed polysaccharides (phycocolloids) by vibrational spectroscopy (FTIR-ATR and FT-Raman)," Food Hydrocolloids, vol. 23, no. 7, pp. 1903-1909, 2009.

[39] J.-W. Rhim and L.-F. Wang, "Preparation and characterization of carrageenan-based nanocomposite films reinforced with clay mineral and silver nanoparticles," Applied Clay Science, vol. 97-98, pp. 174-181, 2014.

[40] S. Roy and T. K. Das, "Effect of biosynthesized silver nanoparticles on the growth and some biochemical parameters of_@@ Aspergillus foetidus_," Journal of Environmental Chemical Engineering, vol. 4, no. 2, pp. 1574-1583, 2016.

[41] R. Priyadarshi, B. Sauraj, Y. S. Kumar, and Y. S. Negi, "Chitosan film incorporated with citric acid and glycerol as an active packaging material for extension of green chilli shelf life," Carbohydrate Polymers, vol. 195, pp. 329-338, 2018.

[42] R. Priyadarshi, S.-M. Kim, and J.-W. Rhim, "Pectin/pullulan blend films for food packaging: effect of blending ratio," Food Chemistry, vol. 347, 2021.

[43] R. Priyadarshi and Y. S. Negi, "Effect of varying filler concentration on zinc oxide nanoparticle embedded chitosan films as potential food packaging material," Journal of Polymers and the Environment, vol. 25, no. 4, pp. 1087-1098, 2017.

[44] S. Shankar and J. W. Rhim, "Amino acid mediated synthesis of silver nanoparticles and preparation of antimicrobial agar/silver nanoparticles composite films," Carbohydrate Polymers, vol. 130, pp. 353-363, 2015.

[45] J.-F. Su, Z. Huang, X.-Y. Yuan, X.-Y. Wang, and M. Li, "Structure and properties of carboxymethyl cellulose/soy protein isolate blend edible films crosslinked by Maillard reactions," Carbohydrate Polymers, vol. 79, no. 1, pp. 145-153, 2010.

[46] E. A. Vogler, "Structure and reactivity of water at biomaterial surfaces," Advances in Colloid and Interface Science, vol. 74, no. 1-3, pp. 69-117, 1998.

[47] W. C. Zeng, Z. Zhang, and L. R. Jia, “Antioxidant activity and characterization of antioxidant polysaccharides from pine needle (Cedrus deodara)," Carbohydrate Polymers, vol. 108, pp. 58-64, 2014.

[48] K.-S. Jeong, "Functional properties of pine needle extract and its antioxidant effect on soybean oil," International Journal of Environmental Science and Technology, vol. 17, no. 10, pp. 1139-1146, 2008.

[49] P. Ezati, R. Priyadarshi, Y.-J. Bang, and J.-W. Rhim, "CMC and CNF-based intelligent $\mathrm{pH}$-responsive color indicator films integrated with shikonin to monitor fish freshness," Food Control, vol. 126, p. 108046, 2021.
[50] R. Priyadarshi, S. Roy, T. Ghosh, D. Biswas, and J.-W. Rhim, "Antimicrobial nanofillers reinforced biopolymer composite films for active food packaging applications - a review," Sustainable Materials and Technologies, no. article e00353, 2021.

[51] P. V. R. K. Ramacharyulu, R. Muhammad, J. Praveen Kumar, G. K. Prasad, and P. Mohanty, "Iron phthalocyanine modified mesoporous titania nanoparticles for photocatalytic activity and $\mathrm{CO}_{2}$ capture applications," Physical Chemistry Chemical Physics, vol. 17, no. 39, pp. 26456-26462, 2015.

[52] Z. Riahi, R. Priyadarshi, J.-W. Rhim, S.-I. Hong, R. Bagheri, and G. Pircheraghi, "Titania nanotubes decorated with $\mathrm{Cu}(\mathrm{I})$ and $\mathrm{Cu}$ (II) oxides: antibacterial and ethylene scavenging functions to extend the shelf life of bananas," ACS Sustainable Chemistry \& Engineering, vol. 9, no. 19, pp. 6832-6840, 2021. 